\title{
¿Es posible el pago de salarios con bitcoins en Uruguay?
}

\author{
Is it possible for wages to be paid with bitcoins in Uruguay?
}

\author{
Juan Diana \\ Universidad de la República, Uruguay \\ ORCID: 0000-0001-6039-2083 \\ Gustavo Gauthier \\ Universidad de la República, Uruguay
}

ORCID: 0000-0002-6339-4129

Correos: jmdiana91@gmail.com; ggauthier@brumcosta.com

Recibido: 23/04/2021

Aceptado: 24/05/2021

\section{Resumen:}

Dado el creciente uso de las criptomonedas a nivel mundial, y dentro de estas el bitcoin (BTC), resulta necesario analizar el marco jurídico aplicable con el fin de detectar posibles cambios o actualizaciones. Uno de los aspectos incluidos en dicho análisis refiere a la posibilidad de efectuar el pago del salario de los trabajadores en bitcoins. En este artículo se busca, desde un abordaje principalmente jurídico y económico, conceptualizar jurídicamente al bitcoin para luego evaluar si la normativa vigente en Uruguay habilita el pago de salarios con esta criptomoneda. Se concluye que en Uruguay existen limitaciones legales para que los salarios mínimos se paguen con otros medios distintos de la moneda nacional, aunque podría establecerse un pago parcial con BTC mediante el mecanismo de los Consejos de Salarios. Para la parte del salario que supere el mínimo no habría inconvenientes, tanto se considere al BTC como dinero privado o como un bien incorporal "común".

Palabras clave: bitcoin; salarios; regulación; fintec; derecho del trabajo; Uruguay.

\begin{abstract}
:
Given the growing use of cryptocurrencies worldwide, within these the bitcoin (BTC), it is necessary to analyze the applicable legal framework to detect possible changes or updates. One of the aspects included in this analysis refers to the possibility of paying workers' wages in bitcoins. This article seeks, from a mainly legal and economic approach, to legally conceptualize bitcoin and then evaluate whether the current legislation in Uruguay enable the payment of salaries with this cryptocurrency. It is concluded that in Uruguay there are legal limitations for minimum wages to be paid with other means than the national currency, although a partial payment with BTC could be established through the mechanism of Wage Councils. For the part of the salary that exceeds the minimum there would be no inconveniences, whether BTC is considered as private money or as a "common" incorporeal good.
\end{abstract}

Keywords: bitcoin; wages; regulation; fintech; labor law; Uruguay. 


\section{Introducción}

El creciente uso de las criptomonedas en el mundo, entre las que se encuentra el bitcoin (BTC), plantea la necesidad de analizar los marcos jurídicos vigentes, a efectos de detectar posibles cambios o actualizaciones que deban sufrir para acompasar las reglas de juego vigentes a los usos, costumbres y requerimientos actuales de los distintos individuos y agentes económicos que componen una sociedad. Esto, en definitiva, representa la esencia y la misión misma del Derecho en tanto instrumento de convivencia social en forma pacífica.

El mencionado planteo no se encuentra motivado por ningún capricho intelectual, ni mucho menos importa un mero ejercicio teórico. Muy por el contrario, resulta de vital importancia si se pretende dar respuesta a los tiempos que corren (en definitiva, si se quiere dar cumplimiento a la misión del Derecho), pudiendo aparejar las conclusiones a las que se arriben serias consecuencias prácticas en las distintas interacciones o, en términos más técnicos, en los diversos "negocios jurídicos" llevados a cabo tanto individual como colectivamente en una sociedad.

Una de las tantas consecuencias derivadas de tales cuestionamientos atañe directamente al Derecho del trabajo y en particular a la posibilidad de efectuar o no el pago de salarios en bitcoins. Como podrá advertirse, este es un punto altamente sensible, partiendo de la consideración del carácter alimentario que se le reconoce al salario.

De hecho, esta posibilidad ya viene siendo planteada a nivel internacional. Por mencionar un ejemplo, ha sido analizada específicamente desde el punto de vista jurídico en España (Diosdado, s. f.; Ramírez, 2021), por lo que no es de extrañar que en un tiempo tenga repercusiones en Uruguay. Como casos concretos se pueden citar el de la empresa Twitter, que en febrero de 2021 anunció estar investigando la posibilidad de abonar los salarios de sus trabajadores en bitcoins (Wright, 2021), o bien el caso del actual alcalde de Miami (EE. UU.), Francis Suárez, quien también en febrero propuso utilizar bitcoin para pagar los salarios de los empleados municipales (Villullas, 2021).

Frente a este panorama este artículo se propone, en primer término, intentar conceptualizar jurídicamente al bitcoin, para luego evaluar la posibilidad del pago de los salarios de los trabajadores. Cabe aclarar desde ya el carácter apriorístico y altamente opinable tanto de las premisas como de las conclusiones vertidas en este trabajo. 


\section{¿Qué es el bitcoin?}

El BTC forma parte de lo que mundialmente se conoce como criptomonedas. A partir de este punto de partida indiscutible, y salvo en lo referido a su abordaje tecnológico (según se mencionará seguidamente), las distintas definiciones o conceptualizaciones del fenómeno revisten — en mayor o en menor medida — cierto grado de polémica o, cuanto menos, pertenecen al universo de las interpretaciones personales, sin perjuicio de los fundamentos técnicos que las sustenten o de los apoyos que puedan hacerse en la escasa normativa vigente en la materia.

Por otra parte, el fenómeno de las criptomonedas (y dentro de esta categoría, el BTC) se puede analizar desde tres abordajes posibles: (1) el tecnológico, a través del cual se explican los mecanismos y las estructuras que posibilitan tanto la existencia como la utilización de la herramienta; (2) el económico, por el que se analiza el rol que cumplen las criptomonedas en la asignación de recursos y en el intercambio de bienes y servicios; y (3) el jurídico, con el que se pretende insertar el fenómeno en el ordenamiento de leyes y regulaciones aplicables dentro de una jurisdicción determinada.

Corresponde aclarar que el presente trabajo centrará su análisis en los últimos dos y, en última instancia, tendrá su objetivo puesto en el tercero. El abordaje tecnológico se utilizará meramente como punto de referencia, concretamente en la mención de determinados conceptos generales que resultan ineludibles.

Avanzando en el intento de dar una definición, se puede decir que BTC es la criptomoneda más conocida y utilizada a nivel mundial. Integra un mismo subtipo con otras criptomonedas, con las que comparte determinadas particularidades, así como hay otros subtipos. No obstante, todas forman parte de un universo de miles de criptomonedas existentes, por lo que el BTC es apenas "la punta del iceberg".

En virtud de lo anterior, se hace necesario ensayar una definición lo más amplia y "aséptica" posible de criptomoneda, que pueda abarcar a todo el universo mencionado. Se propone lo siguiente: una criptomoneda es una representación digital de valor dotada de fungibilidad y divisibilidad, cuya creación y transferencia se produce digitalmente mediante la aplicación de métodos criptográficos, comúnmente utilizada con fines de pago o de inversión. Intentos de caracterización más ampulosos corren el riesgo de definir el género por la especie o bien de insertar en forma innecesaria elementos que dificulten su comprensión. 
Esta definición se puede complementar con algunas conceptualizaciones tecnológicas ineludibles que, se advierte, serán muy generales y tienen como objetivo un mayor entendimiento del tema: las transacciones de criptomonedas se registran mediante la aplicación de una "tecnología de registro distribuido" (un subtipo de esta es la llamada blockchain), lo que en términos llanos puede traducirse en una especie de libro contable digital — que en el caso de BTC es público y abierto - cuyos "asientos contables" se distribuyen en miles de "nodos" (básicamente, supercomputadoras conectadas en red) a efectos de su procesamiento, validación y registro. Todo este mecanismo se da de forma descentralizada, en el sentido de que no hay ninguna autoridad central que concentre la ejecución del proceso.

Concretamente en el caso de la red Bitcoin, muchos de estos nodos se encargan de validar las transacciones realizadas entre los usuarios a cambio de la creación y obtención ("minado") de "nuevas" unidades digitales, esto es de "nuevos" bitcoins, lo cual se efectúa mediante la resolución de complejos problemas matemáticos. Este mecanismo particular de validación es denominado proof of work ("prueba de trabajo"), que no es el único existente ni tampoco el más utilizado hoy por criptomonedas creadas más recientemente que el BTC (2009).

A las personas o empresas dedicadas a esta actividad de validación se las denomina "mineros", en clara analogía a la minería de metales preciosos que, en tiempos pasados, oficiaron como método de intercambio de bienes y servicios. Tanto a la red como al lenguaje o código de comunicación informática que soporta y posibilita los intercambios se los denomina Bitcoin (en mayúscula), mientras que la criptomoneda transada a través de estos se la denomina bitcoin (en minúscula), como se ha venido haciendo en el presente trabajo. Tanto el almacenamiento de BTC como su envío/recepción se produce mediante la utilización de billeteras electrónicas (wallets), las que pueden estar a nombre y en poder del usuario o bien a nombre y en poder de distintos intermediarios, básicamente casas de cambio digitales dedicadas a la compraventa y custodia de criptomonedas (entre otros servicios), denominados exchanges.

Por último, en este repaso general propio del mundo tecnológico y sin perjuicio de que lo que se mencionará pueda ser equiparable a otras criptomonedas del mismo subtipo, se hará referencia a algunas particularidades de BTC que ayudan a la comprensión del fenómeno: 
(i) Desde su origen, BTC tiene predeterminada la cantidad máxima de unidades que podrán ser utilizadas en un futuro: 21 millones de bitcoins. Actualmente se encuentran disponibles para su utilización unos 19 millones de BTC y se estima que se llegará al máximo en el año 2140.

(ii) También desde su origen, BTC tiene predeterminados y automatizados cambios decrecientes en su velocidad de generación o "minado" (“emisión”, si se lo compara con una moneda). Cada disminución de velocidad se denomina halving y podría resumirse en que los "mineros" deberán trabajar cada vez más para recibir la misma cantidad de bitcoins como recompensa por su trabajo (validar transacciones de BTC) o, lo que es igual, para destrabar la utilización de nuevos BTC en su favor.

(iii) Cada BTC puede dividirse en hasta 100 millones de (sub) unidades, denominadas satoshis o sats (en honor al pseudónimo utilizado por su creador anónimo: Satoshi Nakamoto). Dicho de otra manera, un satoshi equivale a 0,00000001 BTC.

(iv) No existe ningún Estado, Banco Central o autoridad similar, así como tampoco ninguna empresa u organismo privado que controle, respalde y/o pueda alterar por sí misma las características o mecanismos de funcionamiento del BTC. Esto, sumado a la característica de la tecnología en la cual se basa (blockchain), hace del BTC la criptomoneda descentralizada por excelencia.

Tras esta conceptualización, se intentará determinar su naturaleza jurídica, así como analizar la situación concreta de Uruguay.

\section{Naturaleza jurídica del bitcoin y su panorama en la legislación uruguaya}

En primer término, corresponde señalar que, hasta la fecha, en Uruguay no existe una definición jurídica de criptomoneda y, por tanto, de BTC. No obstante, cabe advertir que a los efectos de la regulación en materia de prevención del lavado de activos y el financiamiento del terrorismo, resulta aplicable la definición de "activos virtuales" dada por el Grupo de Acción Financiera Internacional (organismo internacional dedicado al 
combate de los referidos delitos, en adelante GAFI) ${ }^{1}$ y que se encuentra vigente desde junio de 2019. La base de esta definición fue tomada para elaborar la ensayada en el apartado anterior, pero fue reformulada para lograr una mayor precisión a la hora de conceptualizar específicamente a las criptomonedas. La definición del GAFI pretende ser omnicomprensiva de los activos virtuales existentes - al menos a la fecha de su elaboración - lo cual implica una categoría mucho más amplia dentro de la cual se encuentran las criptomonedas. Se insiste aquí, una vez más, en la idea de que el BTC es solo la "punta del iceberg".

Frente a este panorama, y a partir de los escasos elementos disponibles, corresponde recurrir a los aportes de la ciencia económica para intentar desentrañar la naturaleza jurídica del BTC y poder así abordar esta faz del fenómeno. Como primer paso, es necesario observar las finalidades del uso de criptomonedas. No es novedad que el Derecho suele "correr detrás de la realidad", intentando acompasar sus reglas a los (nuevos) usos y costumbres de la sociedad a la que sirve en un tiempo y en un espacio determinado. Esto hace del Derecho una herramienta "viva", mutable en esencia.

En este sentido, se advierte sin mayor esfuerzo que las criptomonedas son utilizadas con fines de pago y/o de inversión, elementos que suelen recogerse en los escasos textos normativos existentes a nivel mundial, tal es el caso de la definición de activos virtuales del GAFI anteriormente referida.

Atendiendo primeramente a la finalidad de inversión, y a partir de lo desarrollado en el apartado anterior, se observa con claridad que BTC no otorga a sus tenedores derecho alguno frente a ningún tercero concreto: no hay un emisor, no hay un derecho de crédito ni tampoco un derecho de inversión, entendido como aquel derecho de participación patrimonial en la suerte de una empresa, entidad o proyecto (tal y como sucede con los bonos, las acciones, las obligaciones negociables, los certificados de participación, etc.). Lo único que se verifica mediante la adquisición de un bitcoin es un derecho de propiedad sobre ese bien, en virtud de lo cual a nuestro juicio debe descartarse la finalidad de inversión como elemento jurídico definitorio. Esto es sin perjuicio de la

\footnotetext{
${ }^{1}$ El GAFI define 'activos virtuales' como la "representación digital de valor que puede comercializarse o transferirse digitalmente, y que puede utilizarse con fines de pago o inversión. Los activos virtuales no incluyen las representaciones digitales de las monedas fiduciarias, los valores y otros activos financieros que ya se contemplan en otras partes de las Recomendaciones del GAFI" (Grupo de Acción Financiera Internacional, s. f.).
} 
efectiva existencia de dicha finalidad en su uso corriente, que hoy incluso debe reconocerse como la predominante.

En términos más llanos, y ejemplificando por el absurdo, si en un futuro se comienzan a utilizar sillas con las mismas finalidades que hoy se utiliza el BTC, la adquisición de sillas podrá encubrir una especulación con el aumento de su valor a futuro (momento en el cual se venderán y se obtendrá una ganancia), pero eso no otorga un derecho frente a ningún tercero concreto, elemento distintivo de lo que técnicamente correspondería llamarse "inversión". A este respecto, se entiende que para hablar de verdadera inversión desde el punto de vista técnico corresponde apegarse al criterio establecido en la definición de "valor" del artículo 13 de la Ley de Regulación del Mercado de Valores, N. ${ }^{\circ}$ 18.627, del 02 de diciembre de 2009, disposición que resulta sumamente clarificadora. ${ }^{2}$

Por otra parte, ¿qué sucede con la finalidad de pago? A partir de las observaciones del fenómeno puede verse cómo BTC viene siendo aceptado cada vez más como un método global de intercambio de bienes y servicios, en virtud de lo cual resulta inevitable su asimilación con el dinero. A modo de ejemplo, cabe mencionar los casos de importantes empresas que han dado señales de una posible aceptación de BTC como medio de pago o que directamente ya han incorporado esta criptomoneda: Tesla (Sánchez, 2021), Starbucks (López, 2021), MicroStrategy (Suberg, 2020), MasterCard ("Mastercard se suma”, 2021), Visa (“Confirmado", 2021) y PayPal (“Avanza la revolución”, 2021). Asimismo, entidades bancarias han anunciado la prestación de servicios de custodia de esta criptomoneda. Tal es el caso de BBVA ("BBVA lanza en Suiza”, 2020), Goldman Sachs (“Goldman Sachs planea”, 2021) y BNY Mellon (Huillet, 2021), entre otras.

En la misma línea, hoy en día se registran aumentos en las cantidades de transacciones de compraventa de bienes entre particulares cuyo medio de pago es el BTC. Esta tendencia viene dándose, por ejemplo, en materia de inmuebles en Argentina y España (Garrido, 2021), donde se da la particularidad de que la intervención notarial incluye la corroboración de la transferencia desde la wallet del comprador hacia la wallet

\footnotetext{
2 “Artículo 13 (Definición). Se entenderá por valores, a los efectos de la presente ley, los bienes o derechos transferibles, incorporados o no a un documento, que cumplan con los requisitos que establezcan las normas vigentes. Se incluyen en este concepto las acciones, obligaciones negociables, mercado de futuros, opciones, cuotas de fondos de inversión, títulos valores y, en general, todo derecho de crédito o inversión" [cursivas añadidas].
} 
del vendedor, pero cada vez más el fenómeno va incluyendo bienes y servicios mucho más "cotidianos" (Barca, 2021).

También es destacable la aparición de herramientas creadas exclusivamente a los efectos de utilizar bitcoin como un método de pago, concretamente tarjetas de débito que operan con esta criptomoneda (entre otras). Tal es el caso del reciente lanzamiento de la Lemon Card, desarrollada por la empresa argentina de tecnología financiera Lemon Cash (Méndez, 2021) o la aparición de la Binance Card, ${ }^{3}$ desarrollada por la empresa Binance (uno de los exchanges de criptomonedas más reconocidos en el mundo) en asociación con la mundialmente conocida entidad de pagos Visa ("Presentamos Binance Card", 2020).

Naturalmente, a esto debe adicionársele los planteamientos surgidos a nivel global respecto de la posibilidad de pagar salarios con bitcoins que, en definitiva, configuran el eje central del presente análisis.

En vista de este panorama, y si se opta por considerar al BTC como dinero, conviene comenzar destacando que en Uruguay no hay una definición jurídica que pueda asistir en tal sentido. Esto a pesar de que el Código Civil Uruguayo (en adelante C.C.U.) incluye un total de sesenta y siete referencias expresas al "dinero", siendo incluso un elemento determinante en la aplicación de varias figuras o institutos jurídicos que dependen directamente de la verificación o no de dicho concepto en el negocio o hecho jurídico que se analice. ${ }^{4}$ Lo propio hace el Código de Comercio de Uruguay, que registra un total de cuarenta y seis menciones expresas al "dinero", aunque sin definirlo.

Por su parte, el Decreto-Ley N. ${ }^{\circ}$ 14.500, del 08 de marzo de 1976, sobre actualización de obligaciones en moneda nacional, realiza dos únicas referencias expresas al "dinero", a partir de las cuales cabe concluirse que dicha norma no concibe el género (dinero) sin asociarlo a la especie (moneda), lo que a nuestro juicio se explica en virtud de su finalidad y no a raíz de un error conceptual.

\footnotetext{
${ }^{3}$ 〈https://www.binance.com/es/cards〉

${ }^{4}$ El C.C.U. contiene asimismo algunas menciones a la "moneda" (que como se verá más adelante es una especie dentro del género "dinero"). Establece por ejemplo la presunción de que "toda obligación contraída a pagar en moneda corriente o sin expresar su especie, se entenderá que es en moneda nacional" (art. 1458, inc. 2). La Constitución de la República recorre un camino similar al referir a la moneda (sin manifestarse sobre el concepto de dinero) en dos oportunidades: al incluir la variación del valor de la moneda en las indemnizaciones por expropiaciones (art. 32) y al establecer la potestad de la Asamblea General de "justificar el peso, ley y valor de las monedas; fijar el tipo y denominación de las mismas, y arreglar el sistema de pesas y medidas" (art. 85, num. 10).
} 
La Carta Orgánica del Banco Central del Uruguay ${ }^{5}$ hace una única referencia expresa al "dinero", estableciendo en su artículo 24 la potestad regulatoria de dicho ente sobre "el funcionamiento del mercado de dinero y de cambios", pero sin establecer definición alguna al respecto. ${ }^{6}$

Para no extender innecesariamente la exposición, se mencionará el hecho de que igual camino recorren diversas leyes relativas al sistema de intermediación financiera (Decreto-Ley N. ${ }^{\circ} 15.322$ ), sociedades comerciales (Ley N. ${ }^{\circ} 16.060$ ), usura (Ley N. ${ }^{\circ} 18.212$ ), sistema de pagos (Ley N ${ }^{\circ} 18.573$ ) y mercado de valores (Ley N. ${ }^{\circ} 18.627$ ), sin perjuicio de otras leyes no estrictamente relacionadas a la materia que también hacen referencia al "dinero" sin definirlo o, en el mejor de los casos, asumiendo que se trata de "moneda" (nacional o extranjera).

Este repaso del panorama legal nacional en relación con el concepto de dinero concluye con la mención al caso particular de la Ley N. ${ }^{\circ} 19.210$, del 29 de abril de 2014 (Ley de Inclusión Financiera, en adelante LIF), que inserta en el ordenamiento jurídico uruguayo el concepto de "dinero electrónico". En su artículo 2 la LIF define al dinero electrónico como "los instrumentos representativos de un valor monetario exigible a su emisor, tales como tarjetas prepagas, billeteras electrónicas u otros instrumentos análogos" que cumplan con determinadas características, tales como su almacenamiento en medios electrónicos, su convertibilidad en efectivo y su no generación de intereses. Como podrá advertirse, más allá de ciertas deficiencias técnicas de la LIF al confundir el dinero con el instrumento o medio que lo soporta, se trata de una definición a los solos efectos del (sub) tipo de dinero que regula la ley, y no una definición general de dinero. En efecto, la LIF tampoco asiste en la materia que se viene analizando.

Sin embargo, existen mecanismos interpretativos en la ley vigente, concretamente el artículo 19 del C.C.U. ${ }^{7}$, que remiten a la aplicación de conceptos estudiados por las ciencias que abordan la temática en cuestión, en este caso la Economía. Dentro del campo

\footnotetext{
${ }^{5}$ Aprobada por Ley N. ${ }^{\circ} 16.696$ de 30.03.1995, con las modificaciones introducidas por las leyes $\mathrm{N}^{\circ} 18.401$ del 24.10.2008, N. ${ }^{\circ} 18.494$ de 5.06.2009, N. ${ }^{\circ} 18.643$ de 9.02.2010, N. ${ }^{\circ} 18.670$, de 20.07.2010, Ley N. ${ }^{\circ} 18.996$ de 7.11.2012 y Ley N. ${ }^{\circ} 19.438$ de 14.10.2016, art. 185.

${ }^{6}$ La Carta Orgánica BCU incluye varias referencias a la "moneda". Las más relevantes son las disposiciones sobre el monopolio de la emisión de billetes, acuñación de monedas y retiro de circulación de billetes y monedas en todo el territorio de la República (art. $7^{\circ}$, literal A) y el curso legal y poder cancelatorio de los billetes emitidos y las monedas acuñadas por el Banco en todo el territorio nacional (art. 25).

7 “Artículo 19. Las palabras técnicas de toda ciencia o arte se tomarán en el sentido que les den los que profesan la misma ciencia o arte; a menos que aparezca claramente que se han tomado en sentido diverso".
} 
de esta ciencia, en términos generales se establece de forma pacífica que cualquier bien calificable como "dinero" debe cumplir con tres funciones básicas:

(i) Servir de unidad de cuenta, esto es, la posibilidad de ser utilizado como referencia en relación al valor de los bienes y servicios, determinado como el equivalente a cierta cantidad de unidades de las que se trate (ej.: "esta casa cuesta 150.000 —unidades de- dólares estadounidenses"). Es una capacidad intersubjetiva de los agentes económicos en relación a la unidad de la que se trate, logrando "pensar los precios" en esa unidad.

(ii) Ser utilizado como método de intercambio de bienes y servicios, aspecto que requiere un acuerdo más o menos generalizado por parte de los agentes económicos. Aquí se hace necesario hacer una distinción con la "economía de trueque", que se caracteriza por el intercambio directo del bien o servicio que las partes necesitan entre sí. Se genera la necesidad de encontrar la contraparte que tiene exactamente lo que uno necesita y, a su vez, que esta necesite exactamente lo que uno tiene para ofrecer, siendo por tanto un sistema más ineficiente que la "economía dineraria" referida bajo la función analizada, donde el dinero (cualquiera sea el bien utilizado como tal) es usado como medio indirecto de intercambio y no como fin en sí mismo.

(iii) Servir como reserva de valor, es decir, tener capacidad para almacenar y conservar poder de compra de bienes y servicios por parte de los individuos a lo largo del tiempo. Esta función es la que, primordialmente, depende del factor intersubjetivo de los agentes económicos que supone la confianza por parte de estos en el bien del que se trate. Si por cualquier motivo los agentes no "depositan" su confianza en dicho bien como método de preservación de valor de su esfuerzo en el transcurso del tiempo, no será posible verificar el cumplimiento de la función bajo análisis.

Como podrá haber advertido el lector, estas funciones tan aparentemente claras y definidas del dinero en realidad adolecen de serios problemas de determinación, orden lógico y eventual relación de causalidad (¿retroalimentada?) entre sí. Y lo que es peor, no toman en cuenta la variable que supone el poder coercitivo de un Estado que fija el "curso legal" (esto es, el poder cancelatorio de obligaciones por imperio de la ley) de lo que 
decide adoptar como su propio dinero (su "moneda"), factor que se encarga de transformarlo y mantenerlo "artificialmente" como tal. Esto último puede fácilmente comprobarse, por ejemplo, en los casos de hiperinflación.

Como corolario de esta variable, que como se dijo no es tenida en cuenta por las funciones económicas del dinero antes referidas, se agrega el hecho de que el curso legal impuesto por un Estado respecto de su dinero suele venir acompañado del monopolio legal por parte de este en su creación. Esto quiere decir que el Estado tiene el monopolio de "emisión" de su dinero, y su violación por parte de los individuos es, a su vez, sancionada penalmente bajo el delito de falsificación de moneda, aspectos todos que reafirman la relatividad con que deben considerarse las funciones antes consideradas a la hora de analizar este fenómeno.

Hechos estos reparos, pero continuando con la asistencia que brinda la Economía en el análisis, se agrega que para que las funciones del dinero antes desarrolladas puedan cumplirse en debida forma es condición sine qua non el hecho de que el bien analizado (es decir, aquel respecto del cual se esté evaluando su condición de "dinero") posea ciertas características o propiedades, a saber:

(i) Fungibilidad. Implica la capacidad de que las unidades del bien sean perfectamente sustituibles entre sí, sin que por ello se altere el valor o la consideración que se tiene sobre este. Ninguna unidad del bien puede revestir características particulares que la diferencien de otra unidad de ese mismo bien.

(ii) Divisibilidad. El bien debe poder ser dividido en unidades o subunidades, de manera tal de permitir ejecutar transacciones en distintos niveles y/o por distintas cantidades dentro de la comunidad en la que pretende ser utilizado.

(iii) Durabilidad. Implica poseer cualidades físicas y/o virtuales que le permitan perdurar, de manera tal de poder desarrollar la capacidad de almacenar valor a futuro a los usuarios.

(iv) Portabilidad. Para que el bien pueda ser utilizado en forma masiva, debe tener propiedades que lo hagan fácilmente transportable $-\mathrm{y}$ por tanto utilizable - de un lugar a otro.

(v) Escasez. El bien debe ser relativamente escaso, de manera tal de conservar cierto nivel de apreciación frente a otros bienes y/o servicios. En este punto 
es importante mencionar la incidencia que tiene la posibilidad y/o el costo de apropiación, producción o fabricación del bien.

(vi) Liquidez. Esto implica la capacidad del bien de ser fácil y rápidamente convertido por otros bienes y/o servicios, sin que ello implique altos costos de transacción.

Si bien estas propiedades son considerablemente más fáciles de evaluar en comparación con las funciones del dinero, no están exentas de dificultades interpretativas y/o de valoraciones subjetivas a la hora de analizar el fenómeno en la realidad, principalmente en relación con la liquidez y a la escasez, propiedades cuya verificación terminan siendo de vital importancia para el cumplimiento de las referidas funciones.

En similar sentido a lo anterior, cabe reiterar aquí la relatividad de la teoría frente a la incidencia del poder coercitivo del Estado, quien mediante la "oficialización de su moneda" (en los términos analizados anteriormente a la hora de abordar las funciones del dinero) puede dotar de liquidez y, a su vez, controlar la escasez de este tipo de dinero.

A efectos de profundizar en la posibilidad de considerar el bitcoin como "dinero", y con la intención de ilustrar acerca del origen mismo del dinero, resulta imprescindible acudir a la opinión de economistas de la talla de Carl Menger:

Sólo podemos entender el origen del dinero si aprendemos a considerar el establecimiento del procedimiento social del cual nos estamos ocupando como un resultado espontáneo, como la consecuencia no prevista de los esfuerzos individuales y especiales de los miembros de una sociedad que poco a poco fue hallando su camino hacia una discriminación de los diferentes grados de liquidez de los productos (Menger, 1892, p. 10).

Menger agrega que "el dinero no ha sido generado por la ley. En sus orígenes es una institución social y no estatal. La sanción por parte de la autoridad del Estado constituye una noción que le es ajena" (p.14). En similar sentido, el economista Ludwig von Mises ilustra ampliamente sobre los orígenes del dinero:

En los estadios primitivos de la historia del dinero existían incluso mercancías monetarias cuyas cualidades naturales excluían terminantemente su empleo como dinero al cabo de cierto tiempo. Un buey o un saco de trigo no pueden estar en circulación siempre; más tarde o más 
temprano se destinarán al consumo a fin de que aquella parte de su valor que no depende de su empleo como moneda no disminuya como consecuencia del deterioro de su substancia. Por otra parte, en un sistema monetario desarrollado encontramos dinero-mercancía, del que grandes cantidades permanecen constantemente en circulación sin que se consuman o se empleen en la industria; dinero-crédito, cuyo fundamento, el título de pago, nunca se usa; y posiblemente incluso el dinero-signo, que no tiene otro uso que el de dinero" (Von Mises, 1997, p. 77).

Sobre el tema, el Premio Nobel en Economía Friedrich Hayek (1996) afirma: "El dinero se define habitualmente como el medio de cambio generalmente aceptado; pero no hay razón para que dentro de una comunidad determinada no pueda haber más de un tipo de dinero generalmente (o al menos extensamente) aceptado" (p. 55). Asimismo, agrega:

Aunque habitualmente supongamos que existe una línea determinada para distinguir lo que es dinero de lo que no lo es - y la ley generalmente intenta hacer tal distinción-, en lo que se refiere a los efectos causales de los eventos monetarios no se aprecia una diferencia clara. Nos encontramos más bien con una continuidad en la que objetos con distintos grados de liquidez, o cuyos valores fluctúan independientemente de los demás, se confunden unos con otros en la medida en que funcionan como dinero (Hayek, 1996, p. 55).

Con su estilo por momentos punzante, Hayek añade:

La ficción legal, introducida para facilitar el trabajo del abogado o del juez, que sostiene que sólo hay una cosa claramente definida que se llame "dinero", rigurosamente distinguible de otras, nunca fue cierta en lo que se refiere a los efectos característicos del dinero. Sin embargo, ha sido altamente nociva, ya que ha conducido a que, en algunos casos, sólo pueda utilizarse el "dinero" emitido por el gobierno, o que siempre tenga que haber algo que pueda llamarse el "dinero" de un país. Ha llevado también, como veremos más tarde, al desarrollo en la teoría económica de una explicación del valor de las unidades monetarias que no es de gran ayuda para los problemas de que aquí tratamos, aunque a través de sus supuestos simplificados suministra algunas aproximaciones útiles (Hayek, 1996, pp. 56-57). 
Por otra parte, y ya desde una visión más antropológica, resulta igualmente interesante e ilustrativa del fenómeno la apreciación del profesor Jack Weatherford:

El dinero no se da en la naturaleza y no hay ninguna versión de él, o un elemento análogo, en el reino animal. El dinero, al igual que el lenguaje, es exclusivamente humano. Constituye una nueva forma de pensar y actuar que modificó el mundo al instante (Weatherford, 1998, p. 53).

Asimismo, destacan en su obra una serie de afirmaciones relativas al dinero electrónico que son inesperadamente premonitorias en relación con el tema analizado aquí — como se verá más adelante_ - y que pueden sintetizarse en los siguientes pasajes:

La humanidad ha empleado el dinero durante veinticinco siglos. En todo ese tiempo, el dinero ha crecido y se ha estancado alternativamente, ha sido abandonado y ha resurgido, ha sido degradado y restaurado, inflado y deprimido. Después de un período particularmente largo y exitoso de empleo de un dinero con base en el oro y la plata, el recurso mutó una vez más en el siglo veinte y se transformó en señales electrónicas que en un principio parecieron poco más que una modalidad contemporánea y más eficaz de la tinta, con la cual se registraban ahora los números y la información. Pero esta nueva mutación ha demostrado ser más flexible de lo que pudo predecir ningún académico o comerciante, y ningún gurú o psíquico. Libre al fin de los confinamientos del tiempo y el espacio, del control de cualquier gobierno, de ningún conglomerado de grandes corporaciones y hasta de las fuerzas habituales de la economía, el dinero ha evolucionado hasta otro nivel, para convertirse en una entidad absolutamente nueva. Y nunca más será lo que alguna vez fue (Weatherford, 1998, pp. 329-330).

En la misma línea, Weatherford concluye el capítulo dedicado al análisis del dinero electrónico, afirmando que:

Al acercarnos al fin del sistema de la divisa nacional controlada por los respectivos gobiernos, comienza a perfilarse un mercado enteramente nuevo en el ciberespacio, donde operan muy diversos tipos de dinero en forma simultánea. Como el antiguo pueblo de Yap, los futuros usuarios del dinero se verán confrontados a un abrumador despliegue de tipos de dinero, 
con usos distintos y en ocasiones muy específicos. Como las conchitas multicolores y las tabletas de piedra arenisca de varios tamaños, el dinero del futuro vendrá en muchos tamaños y formas que dependerán bastante menos del país de origen como de la clase y el tipo de persona que los emplee.

Nos hallamos en el último tramo de un largo proceso de evolución histórica, en que el dinero cambió de las conchitas y las mercancías a un complejo sistema de monedas de carácter global. Estamos a la vez en el inicio de lo que promete ser la mayor revolución social y cultural desde la invención del dinero (p. 332).

A partir de estas herramientas conceptuales, corresponde evaluar si el BTC puede ser calificado como dinero desde el punto de vista jurídico. Por las razones ya esgrimidas, debe recordarse aquí que se ha descartado la finalidad de inversión como elemento jurídico característico del BTC, aun cuando hoy todavía siga siendo la finalidad preponderante para la que se utiliza.

Tomando en cuenta la ausencia de definiciones legales y la remisión que en este sentido hace el artículo 19 del C.C.U., se considerarán las funciones y propiedades del dinero anteriormente identificadas (con los reparos oportunamente efectuados respecto de ambas), así como los aportes de los autores citados.

En cuanto a la función de unidad de cuenta, se considera que hoy no es cumplida por el BTC. En términos más sencillos, a la fecha los precios no son pensados en bitcoins, sino que resulta necesario establecer una equivalencia en una moneda "fiat" a tales fines. Para el caso de Uruguay esto se efectúa con referencia al dólar estadounidense (nótese la paradoja de no establecer la equivalencia con la propia moneda, el peso uruguayo). No obstante, y sin perjuicio de la relatividad con que deben tomarse las funciones del dinero por los motivos ya expresados, se agrega aquí que esta función es comúnmente mencionada como la última en consolidarse desde el punto de vista cronológico, en el proceso de transformación de un bien en "dinero".

Respecto de la función como método de intercambio, la evidencia relevada a lo largo del presente trabajo permite concluir que es efectivamente cumplida por el BTC, aunque hoy más no sea de forma imperfecta, encontrándose "pendiente" la utilización como tal con mayor alcance y cotidianeidad a nivel global. 
En cuanto a la función de reserva de valor, se entiende que es la que hoy cumple BTC en mayor medida, si se considera la evolución de su valor a largo plazo, concretamente desde sus primeras señales de consolidación en el año 2013 a la fecha. De hecho, esta es la función con la cual más se suele identificar a esa criptomoneda una vez que se la deslinda de su finalidad de "inversión" con fines especulativos. Al respecto, cabe citar algunas opiniones de distintos profesionales, medios y/o entidades de la industria financiera, quienes se animan a plantear la idea de que BTC se está transformando progresivamente en el "oro digital", es decir que está sustituyendo al metal precioso en la utilización como "refugio de valor" frente a contextos macroeconómicos de incertidumbre (Aparicio, 2021; “Bitcoin vs oro”, 2021; James, 2021).

Sin perjuicio de lo anterior, debe advertirse que este tema no está exento de polémica, dada la "volatilidad", es decir, la producción de cambios brucos en la cotización del bitcoin medida en dinero "fiat" (dólar, euros, yenes, etc.) que aún mantiene el BTC, frente a lo cual se reafirma la importancia de visualizar la evolución en el largo plazo, así como la incidencia que en dicha volatilidad tiene la finalidad de "inversión" especulativa que sobre el bien sigue predominando hoy en día, la cual como se ha mencionado, debe descartarse como elemento jurídico definitorio del BTC.

Por su parte, en cuanto a las propiedades del dinero, y tomando en cuenta la descripción del BTC analizada en el apartado anterior, se observa con claridad el pleno cumplimiento de las primeras cinco de ellas: fungibilidad, divisibilidad, durabilidad, portabilidad y escasez. Respecto de la liquidez, se entiende que, si bien no es cumplida en forma plena, hoy en día existen mecanismos tecnológicos y multiplicidad de servicios que vienen aumentando considerablemente esta propiedad, en tanto operan como herramientas que aumentan la facilidad, rapidez y bajos costos de las transacciones que se pretenden ejecutar en BTC, por lo que es de esperarse que en el mediano plazo sea considerado como un bien de alta liquidez.

Asimismo, y considerando las referencias teóricas de los autores relevadas a lo largo del presente trabajo, como último corolario en la evaluación se menciona que la existencia de un bien calificable como dinero es independiente al respaldo o autoridad que sobre este pueda imponer un Estado, pudiéndose incluso verificar la existencia de dinero en concurrencia con la moneda estatal. Dicho de otra manera, el respaldo de una autoridad pública no es un elemento constitutivo del dinero, en tanto su esencia radica en un pacto social cuyo asiento es la confianza colectiva y generalizada sobre un 
determinado bien por parte de una comunidad de individuos. A nuestro entender, esta es justamente la situación en la que se encuentra el bitcoin.

En consecuencia, y a nuestro juicio, es posible afirmar que el BTC se encuentra en condiciones de ser calificado desde una perspectiva jurídica como "dinero digital privado", por resultar la calificación que mejor se adapta a su lógica, siendo la que permite de mejor manera razonar la arquitectura jurídica necesaria para readaptar el Derecho a los tiempos que corren. Ello con todas las implicancias que tal calificación pueda tener (financieras, tributarias, de seguridad social, etc.), dentro de las cuales naturalmente se encuentra la que se desarrolla en el apartado siguiente en materia laboral.

En línea con lo anterior, y siempre a riesgo de equivocarnos, consideramos altamente probable que a mediano plazo el BTC se consolide en los hechos como dinero, afianzando cada vez más las funciones de unidad de cuenta (pensar los precios en BTC), método de intercambio (comprar en BTC) y reserva de valor (ahorrar en BTC). En efecto, y en una lógica similar a la planteada por el profesor Weatherford a la hora de realizar sus predicciones sobre el dinero electrónico, creemos que el BTC nos enfrenta hoy a una vuelta a los orígenes "privados" del dinero, entendido como aquel que no es emitido, respaldado ni controlado por ninguna autoridad pública, como en la antigüedad supieron ser las conchas marinas, las semillas de cacao, las piezas de ámbar, marfil o jade, las cuentas ornamentales, los clavos, la sal y los metales preciosos. Solo que esta vez se presenta en su versión más moderna de la mano de la tecnología, a lo que se agrega una fuerte tendencia a la aceptación global.

En línea con la conceptualización del BTC como "dinero digital privado", puede citarse una sentencia del Estado de Texas, en un juicio iniciado por la Comisión de Bolsa y Valores de los Estados Unidos (Securities and Exchange Commission, SEC por su denominación en inglés) contra el Sr. Trendon T. Shavers y su empresa Bitcoin Savings and Trust, en el marco de una estafa piramidal o bajo el "esquema Ponzi" ejecutada con BTC y que puede calificarse como leading case en la materia. El juez de la causa determinó que "bitcoin es una moneda digital descentralizada que puede utilizarse para comprar bienes y servicios en línea, o negociarse en intercambios en línea por monedas convencionales, incluido el dólar estadounidense", sentando así un interesante precedente. $^{8}$

\footnotetext{
${ }^{8}$ Securities and Exchange Commission v. Shavers et al, No. 4:2013cv00416 - Document 88 (E.D. Tex. 2014).
} 
En similar sentido, cabe mencionar la legislación vigente en la materia en el Estado de Wyoming (EEUU), la cual clasifica a las criptomonedas en tres categorías: activos digitales de consumo, valores digitales y monedas virtuales, estableciendo que cualquier activo digital que caiga en alguno de estos criterios será considerado como propiedad personal intangible y gozará del mismo trato legal que aplica para el dinero fiduciario (Di Matteo, 2019).

En definitiva, a la luz de lo expuesto y con independencia de las soluciones concretas que resulten de recibo a la hora de actualizar la legislación uruguaya, consideramos que un ordenamiento jurídico que pretenda adaptarse a las necesidades actuales deberá necesariamente partir del BTC como "dinero digital privado".

Por último, resta hacer una breve mención a la postura adoptada por el Banco Central del Uruguay (BCU), en tanto autoridad monetaria del país. Desde el año 2018 a la fecha, con mayor o menor énfasis, el BCU ha venido sosteniendo la idea de que el BTC es un bien incorporal "común" que no reviste las características del dinero (Yelpo, 2018a), ${ }^{9}$ y que se utiliza meramente con fines de inversión especulativa (postura que comparte con la mayoría de los reguladores financieros en América Latina). Esto es sin perjuicio de haber dejado constancia en reiteradas ocasiones de su potestad legal de regulación del sistema de pagos en virtud de la ley N. ${ }^{\circ} 18.573$, del 13 de setiembre de 2009, así como también de haber anunciado su intención de avanzar en la regulación de las criptomonedas desde la óptica de la prevención del lavado de activos y el financiamiento del terrorismo, en cumplimiento de las recomendaciones del GAFI ("El BCU estudiará costos”, 2020).

\section{¿Es posible pagar el salario con bitcoins?}

Un primer abordaje del tema puede efectuarse en el plano dogmático, desde la perspectiva de la morfología del salario, a efectos de distinguir las partes que lo componen, qué elementos lo integran y qué alcance y régimen jurídico especial posee cada una de ellas (Plá Rodríguez, 1956, p. 25).

\footnotetext{
${ }^{9}$ Yelpo (2018b) también afirma que "en los hechos, en todos los casos, sus tenedores (de criptomonedas) buscan el 'respaldo' o la captación de efectivo, ya que cotizan y 'valen' en función del dólar americano u otra moneda genuinamente fuerte. Esto es tan así que las criptomonedas no han logrado adquirir relevancia como instrumento de cambio, captando fundamentalmente la atención de los especuladores" (p. 82).
} 
Siguiendo en parte a la doctrina italiana (Barassi, 1953, p. 42), ${ }^{10}$ Plá Rodríguez distingue dos partes en el salario: un elemento básico consistente en una suma fija de dinero y los elementos marginales, que pueden consistir en especie o en dinero y que por lo general se agregan al elemento básico (Plá Rodríguez, 1956, p. 25).

Ahora bien, como afirma este autor: "El elemento básico, o sea la suma fija y estable de dinero que constituye ordinariamente el núcleo principal del salario, es la retribución directa e inmediata que percibe el trabajador de su empleador" (p. 25). En este sentido, Plá Rodríguez sostiene que pueden existir casos donde esto no se verifique y ello no descarta la posibilidad de estar frente a un salario o que se salga del ámbito del contrato de trabajo, al punto de afirmar que "ni siquiera existe siempre", refiriéndose al dinero como integrante del elemento básico del salario (p. 26).

De alguna manera, el anterior temperamento puede verse reflejado también en el artículo 3.1 del Convenio Internacional del Trabajo N. ${ }^{\circ} 95,{ }^{11}$ que refiere a la exigencia de abonar los salarios en moneda de curso legal cuando los salarios "deban pagarse en efectivo", dejando abierta la posibilidad que puedan abonarse mediante otros mecanismos o instrumentos que no sea en moneda de curso legal, cuando no se paguen en efectivo.

En este sentido, el artículo $3^{\circ}$ del CIT 95 admite que la autoridad competente permita otra forma de pago del salario mediante cheques o giro postal "cuando este modo de pago sea de uso corriente o sea necesario a causa de circunstancias especiales, cuando un contrato colectivo o un laudo arbitral así lo establezca, o cuando, en defecto de dichas disposiciones, el trabajador interesado preste su consentimiento". ${ }^{12} 13$

\footnotetext{
${ }^{10}$ Barassi (1953) lo expresaba en estos términos: "La retribución básica es el elemento fijo, la plataforma fundamental de la que surgen los aumentos ulteriores... a ella se agregan (más o menos en relación a su monto) los ulteriores elementos marginales variables" (p. 42).

${ }^{11}$ Ratificado por Uruguay por Ley N. ${ }^{\circ} 12.030$ de 27 de noviembre de 1953.

${ }^{12}$ En la legislación uruguaya, el Decreto N. ${ }^{\circ} 462 / 970$, concede a la Inspección General del Trabajo y de la Seguridad Social, la facultad de autorizar el pago de salarios mediante cheques girados contra bancos de plaza, sujeto a la aprobación del Ministerio de Trabajo y Seguridad Social.

${ }^{13}$ Asimismo, el propio CIT 95 habilita que los Miembros planteen excepciones a la aplicación de algunas de sus disposiciones, cuando en artículo $2^{\circ}$ prevé que "la autoridad competente, previa consulta a las organizaciones de empleadores y de trabajadores, cuando dichas organizaciones existan y estén directamente interesadas, podrá excluir de la aplicación de todas o de cualquiera de las disposiciones del presente Convenio a las categorías de personas que trabajen en circunstancias y condiciones de empleo tales que la aplicación de todas o de algunas de dichas disposiciones sea inapropiada y que no estén empleadas en trabajos manuales o estén empleadas en el servicio doméstico o en trabajos análogos". Este recurso debe efectuarse en la primera Memoria remitida por el Estado parte o Miembro de la OIT posterior a la ratificación del Convenio, no siendo posible recurrir al mismo con posterioridad, en mérito a que el propio Convenio previene que "ningún Miembro podrá hacer exclusiones ulteriormente, salvo con respecto a las categorías de personas así indicadas".
} 
Naturalmente que hasta el momento tanto la doctrina como las normas internacionales y nacionales ${ }^{14}$ siempre tomaron como referencia para el pago de los salarios el concepto de dinero asociado a su versión fiduciaria, de curso legal, respaldado por una autoridad central, es decir, "dinero" como sinónimo de moneda de un Estado. En modo alguno han considerado la posibilidad de la existencia de dinero digital privado en los términos que se han conceptualizado para el BTC en el presente trabajo, sin perjuicio que la regulación de las criptomonedas actualmente se encuentra en carpeta de varias autoridades y parlamentos del mundo.

En referencia a la forma de retribución, Plá Rodríguez (1994) señalaba que "la evolución tendió también hacia soluciones más amplias para abarcar todo tipo de retribución, fuera fija o variable, en dinero o en otras ventajas, siempre que estuviera vinculada con el otro polo de la relación" (p. 8).

De modo que se podría concluir, en forma preliminar, que en el plano dogmático nada obsta a que el elemento básico del salario se componga de otro tipo de bienes o valores, distintos al dinero efectivo o fiduciario, a condición de que cumpla con una condición fundamental: que implique siempre una "ventaja económica" para el trabajador para poder ser conceptualizado como salario (Plá Rodríguez, 1994, p. 10). ${ }^{15}$

Un segundo abordaje necesario consiste en relevar la normativa internacional vigente sobre protección del salario, compuesta fundamentalmente por el CIT 95, que establece una serie de condiciones a observar por el empleador al momento de proceder a abonar el salario de los trabajadores y que pueden sintetizarse en las siguientes:

a.- Los salarios abonados en efectivo deberán pagarse exclusivamente en moneda de curso legal.

b.- Está prohibido el pago con pagarés, vales, cupones o cualquier otra forma representativa de la moneda de curso legal.

c.- La autoridad competente podrá autorizar el pago del salario por cheque contra un banco o por giro postal, bajo determinadas condiciones.

d.- La legislación nacional, los contratos colectivos o los laudos arbitrales pueden permitir el pago parcial del salario con prestaciones en especie en las industrias $\mathrm{u}$

\footnotetext{
${ }^{14}$ Por ejemplo, en Francia, ya en 1908 por ley se estableció que "los salarios de los obreros y empleados deben ser pagados en moneda metálica o fiduciaria de curso legal”.

${ }^{15}$ Se parte de la definición de salario de Plá Rodríguez (1994) como "conjunto de ventajas económicas que obtiene el trabajador como consecuencia de su labor prestada en virtud de una relación de trabajo" (p. 10).
} 
ocupaciones en que esta forma de pago sea de uso corriente o conveniente a causa de la naturaleza de la industria u ocupación de que se trate.

e.- En ningún caso se deberá permitir el pago del salario con bebidas espirituosas o drogas nocivas.

f.- El salario debe pagarse directamente al trabajador interesado.

g.- Se deberá prohibir que los empleadores limiten en forma alguna la libertad del trabajador de disponer de su salario.

h.- Los descuentos de los salarios solamente se deberán permitir de acuerdo y dentro de los límites fijados por la legislación nacional, un contrato colectivo o un laudo arbitral.

De acuerdo al CIT, cuando los salarios se paguen en efectivo deben pagarse en moneda de curso legal y solo la autoridad competente podrá autorizar el pago del salario por cheque contra un banco o por giro postal, bajo determinadas condiciones. En este sentido, desde que, como se refiriera supra, el BTC no constituye actualmente una moneda de curso legal ni tampoco implica una orden de pago contra un banco como los cheques, en el marco del Convenio el pago mediante esta criptomoneda no podría sustituir el pago del salario cuando este se pague en efectivo.

No obstante y en el ámbito del sistema normativo de la OIT, corresponde tener presente también lo establecido en el numeral 8 del artículo 19 de su Constitución, que dispone que:

En ningún caso podrá considerarse que la adopción de un convenio o de una recomendación por la Conferencia, o la ratificación de un convenio por cualquier Miembro, menoscabará cualquier ley, sentencia, costumbre o acuerdo que garantice a los trabajadores condiciones más favorables que las que figuren en el convenio o en la recomendación.

Desde esta perspectiva, cabría analizar si el pago del salario en BTC puede considerarse como una condición más favorable al pago del salario en moneda de curso legal como exige la normativa internacional cuando este se paga en efectivo. La respuesta no es sencilla y dependerá de diversos factores, algunos de los cuales a su vez pueden variar en función de la realidad de cada país. Entre estos factores pueden señalarse, básicamente, la variación en la cotización del BTC en moneda de curso legal, las 
posibilidades y condiciones de acceso a la realización en el mercado de los BTC y/o cuán extendida esté su aceptación como medio de pago y los mecanismos de ajuste o actualización de los salarios.

Concretamente, entendemos que para poder considerar el pago de salarios en BTC como una "condición más favorable" en comparación con el pago en moneda de curso legal, se deberían verificar los siguientes factores:

a.- Que existan amplias posibilidades de acceso al mercado para realizar los BTC a moneda de curso legal y/o una extensa aceptación del BTC como medio de pago. Esto va en línea con el proceso de consolidación del bitcoin como dinero.

b.- En ordenamientos o sectores donde no rijan salarios mínimos, la condición más favorable se verificaría cuando la moneda de curso legal se deprecie frente al BTC en un período determinado y sostenido en el tiempo y no a la inversa.

c.- En ordenamientos o sectores donde rijan salarios mínimos, la cotización promedio en moneda de curso legal del BTC verificada en el período de generación del salario (mensual, quincenal, semanal, etc.) multiplicada por la cantidad de BTC pactados como retribución no debería traducirse en una cifra inferior a los mínimos vigentes, considerando asimismo los ajustes periódicos obligatorios que puedan corresponder en cada oportunidad. Se podría considerar incluso la conveniencia de efectuar comparaciones de forma sostenida en el tiempo por períodos mayores a la generación del salario, a cuyos efectos debe relevarse la cantidad suficiente de información pasada, así como dársele seguimiento en el transcurso de su implementación. Por su parte, la comparación antes referida debería hacerse previo descuento de las comisiones que puedan corresponder para la realización de la transacción.

Finalmente, correspondería analizar la legislación interna de cada país en relación con el salario para determinar la existencia de otros obstáculos que puedan obstar el pago en BTC. En el caso uruguayo, corresponde tener presente dos normas donde se regulan aspectos del salario y que tienen que ver con el tema objeto de estudio: por un lado, el artículo 2 de la Ley N. ${ }^{\circ} 10.449$ y por otro el artículo 10 de la LIF (Ley N. ${ }^{\circ}$ 19.210).

La primera de las normas, referida a los salarios mínimos, establece una doble limitación: "Los salarios mínimos serán pagados en moneda nacional, con exclusión de toda otra especie y con eliminación absoluta de todo sistema de trueque, salvo lo dispuesto 
en el artículo 18". Esto impide que los salarios mínimos sean abonados a través de otros medios que no sean la moneda nacional e impide en términos categóricos y contundentes todo sistema de trueque.

De esta manera, no sería posible en Uruguay pagar los salarios mínimos con BTC al no constituir moneda nacional, independientemente que, de acuerdo al desarrollo efectuado supra, la entrega de BTC no puede ser entendido como un trueque. No obstante, es preciso tener presente la salvedad de lo dispuesto en el artículo 18 de la misma Ley:

Los Consejos de Salarios establecerán las deducciones que los patronos podrán hacer sobre los sueldos y salarios por concepto de viviendas y alimentación, así como por los provechos que puedan resultar de la naturaleza del empleo, como ser: comisiones, habilitaciones, propinas, etc.

De esta forma, estos órganos tripartitos podrían establecer que parte de los salarios mínimos se paguen con partidas marginales del salario tanto en dinero como en especie y de este modo podrían llegar autorizar el pago en BTC. Por encima del monto de los salarios mínimos fijados, no sería de aplicación la restricción contenida en el artículo 2 de la Ley N. ${ }^{\circ} 10.449$, por lo cual, abonado el monto del salario mínimo en moneda nacional, la otra parte del salario no se vería afectada.

La LIF, por su parte, establece en sede de pago de nóminas que:

Sin perjuicio de la modalidad de pago en efectivo, el pago de las remuneraciones y de toda otra partida en dinero que tengan derecho a percibir los trabajadores en relación de dependencia, cualquiera sea su empleador, podrá efectuarse a través de acreditación en cuenta en instituciones de intermediación financiera o en instrumento de dinero electrónico.

La norma prevé tanto la modalidad de pago en efectivo como el pago a través de acreditación en cuenta en instituciones de intermediación financiera o en instrumento de dinero electrónico. De todos modos, y sin perjuicio de las observaciones realizadas anteriormente en relación con el alcance de la norma, entendemos que esta disposición no resulta excluyente de otras modalidades de pago como puede llegar a ser el pago en dinero digital privado y, en consecuencia, no resultaría limitativa para el pago en BTC. 


\section{Alternativas para el pago de salarios con bitcoins}

Si el elemento básico del salario no tiene que estar compuesto ni abonarse necesariamente con dinero fiduciario, sino que podría admitirse su pago a través de otro tipo de bienes o instrumentos, entonces no habría impedimento para admitir que la parte básica del salario sea abonada mediante dinero digital privado de acuerdo a la definición propuesta supra. ${ }^{16}$ En este sentido y en virtud del principio de libertad contractual sobre las diferentes formas de retribución, corresponderá a las partes el decidir, en el momento de concluir el contrato, cuál será el modo de remuneración (Camerlynk y Lyon-Caen, 1974, p. 187). Para ello, sí debería exigirse que el pago del salario mediante BTC constituya auténticamente una ventaja económica para el trabajador derivado del contrato de trabajo, de otro modo no podría ser admitido como salario.

Otro problema que puede surgir, a partir de la aceptación del pago del salario en BTC, tiene que ver con su avaluación económica y ello tiene relevancia tanto a efectos de determinar si se cumplen con los salarios mínimos o interprofesionales, así como también respecto del pago de las cotizaciones o aportes a la seguridad social.

De acuerdo a lo mencionado anteriormente, tratándose el BTC de un instrumento cuyo valor en moneda de curso legal puede extraerse a partir de una cotización diaria obtenida a partir de la operativa de compra y venta llevada a cabo en los principales exchanges del mundo (Pérez, 2021) y, como tal, sometida a las reglas generales de oferta y demanda, no habría inconveniente en establecer al final de cada período de generación del salario el valor promedio de esta criptomoneda en el mismo período y, de esa forma, llegar al equivalente de dicho valor en la moneda de curso legal en el país de que se trate, sin perjuicio de las precisiones hechas oportunamente sobre el punto.

De esta manera, en aquellos casos donde exista un salario mínimo que deba ser observado de acuerdo con la actividad y categoría del trabajador, el promedio del valor del BTC en el período de generación del salario traducido a la moneda de curso legal permitiría determinar en cada período si se cumplió con el pago de los salarios mínimos.

Del mismo modo, el valor promedio del BTC en el período de generación del salario traducido a moneda de curso legal constituiría la base de cálculo o materia gravada para las contribuciones o aportes a la seguridad social.

\footnotetext{
${ }^{16}$ Naturalmente, sin perjuicio de las regulaciones específicas que en cada país puedan existir, como en el caso uruguayo con la regulación del pago de los salarios mínimos en moneda nacional.
} 
Finalmente, y con respecto al pago mediante BTC de la parte variable, accesoria o marginal del salario, más allá del básico o del salario mínimo vigente, no se advierten impedimentos de ningún tipo para aceptar al BTC como un elemento marginal más del salario, tanto que se acepte la posición de que se trata de dinero digital privado como se propone en el presente trabajo, o se considere, como lo hace actualmente la autoridad monetaria uruguaya, como un bien incorporal.

\section{Conclusiones}

En virtud de lo desarrollado a lo largo del presente trabajo, cabe extraer las siguientes conclusiones:

1) El creciente uso de las criptomonedas a nivel mundial, y dentro de estas el bitcoin, plantea la necesidad de evaluar los marcos jurídicos vigentes, con el fin de detectar posibles requerimientos de actualización a efectos de dar respuesta a los usos, costumbres y necesidades actuales de la sociedad.

2) El BTC forma parte de lo que mundialmente se conoce como criptomonedas. La temática puede abordarse al menos desde tres enfoques distintos: el tecnológico, el económico y el jurídico. El presente trabajo centró su análisis en los últimos dos abordajes mencionados (con el objetivo puesto en el tercero de ellos), utilizando el abordaje tecnológico meramente como punto de referencia.

3) Una criptomoneda es una representación digital de valor dotada de fungibilidad y divisibilidad, cuya creación y transferencia se produce digitalmente mediante la aplicación de métodos criptográficos, comúnmente utilizada con fines de pago o de inversión. Ubicándose dentro de esta categoría, el BTC reviste algunas particularidades que la transforman en la criptomoneda descentralizada por excelencia.

4) En cuanto a su naturaleza jurídica, y considerando la ausencia de definiciones legales vigentes en nuestro ordenamiento jurídico, por las razones expuestas a lo largo del presente trabajo debe descartarse la finalidad de inversión como elemento jurídico definitorio. Por el contrario, a estos efectos debe atenderse a su finalidad de pago y, en esta línea, es que el BTC puede ser calificado como "dinero digital privado". 
5) Tanto la doctrina como las normas internacionales y nacionales siempre tomaron como referencia para el pago de los salarios el concepto de dinero asociado a su versión fiduciaria, de curso legal, respaldado por una autoridad central (es decir, "dinero" como sinónimo de moneda de un Estado) y en modo alguno la posibilidad de la existencia de dinero privado (digital) en los términos planteados en este trabajo.

6) En el marco de la normativa internacional, en la medida que el BTC no constituye una moneda de curso legal ni tampoco implica una orden de pago contra un banco como los cheques, en principio el pago mediante esta criptomoneda no podría sustituir el pago del salario cuando este se pague en efectivo. Sin perjuicio de esto, cuando el pago del salario en BTC pueda considerarse como una condición más favorable al pago en moneda de curso legal (lo cual depende de diversos factores oportunamente analizados) no existirían impedimentos para admitir dicho medio de pago.

7) En el caso uruguayo, a priori, las limitaciones legales existentes impedirían que los salarios mínimos sean abonados a través de otros medios que no sean la moneda nacional. De esta manera, no sería posible en Uruguay pagar los salarios mínimos con BTC. No obstante, a través del mecanismo de los Consejos de Salarios, podría llegar a establecerse que parte de los salarios mínimos se paguen con BTC.

8) Finalmente, y respecto de la parte del salario que supere el mínimo fijado, no existiría inconveniente en implementar el pago con dicha criptomoneda, tanto se acepte la posición de que se trata de dinero privado (como se propuso en el presente trabajo) o se considere, como lo hace actualmente el Banco Central del Uruguay, como un bien incorporal "común".

\section{Referencias}

Aparicio, L. (8 de enero de 2021). Bitcoin: el nuevo oro de los 'millennials'. El País. Recuperado el 23 de abril de 2021 de https://elpais.com/economia/2021-01-08/bitcoinel-nuevo-oro-de-los-millennials.html

Avanza la revolución "cripto": PayPal permite el pago con Bitcoin y su conversión inmediata a dólares. (30 de marzo de 2021). Infobae. Recuperado el 23 de abril de 2021 de https://www.infobae.com/economia/2021/03/30/avanza-la-revolucion-cripto-paypalpermite-el-pago-con-bitcoin-y-su-conversion-inmediata-a-dolares/ 
Barassi, L. (1953). Tratado de Derecho del Trabajo, Tomo III. Buenos Aires, Argentina: Alfa.

Barca, K. (29 de marzo de 2021). 11 cosas que ya puedes comprar con bitcoin y todavía no te habías enterado. Business Insider. Recuperado el 23 de abril de 2021 de https://www.businessinsider.es/11-cosas-puedes-comprar-bitcoin-no-sabias-836135

BBVA lanza en Suiza servicio para la compraventa y custodia de bitcoins. (10 de diciembre de 2020). El Observador. Recuperado el 23 de abril de 2021 de https://www.elobservador.com.uy/nota/bbva-lanza-en-suiza-servicio-para-lacompraventa-y-custodia-de-bitcoins-20201210101143

Bitcoin vs oro: quién está ganando actualmente esta pelea. (8 de enero de 2021). IProUp. Recuperado el 23 de abril de 2021 de https://www.iproup.com/economia-digital/19648bitcoin-hoy-vale-mas-que-un-lingote-de-oro-de-20-onzas

Camerlynk, G. H., y Lyon-Caen, G. (1974). Derecho del Trabajo. Madrid, España: Aguilar.

Confirmado: Visa apuesta al Bitcoin y se une a la tendencia de Tesla, JP Morgan y PayPal. (18 de marzo de 2021). IProUP. Recuperado el 23 de abril de 2021 de https://www.iproup.com/economia-digital/21378-visa-hizo-oficial-su-apuesta-abitcoin?utm_source=hootsuite

Di Matteo, A. (2 de febrero de 2019). Wyoming aprueba proyecto de ley para reconocer a las criptomonedas como dinero fiat. DiarioBitcoin. Recuperado el 23 de abril de 2021 de https://www.diariobitcoin.com/articulos/noticias/wyoming-aprueba-proyecto-de-leypara-reconocer-a-las-criptomonedas-como-dinero-fiat/

Diosdado, J. (s. f.). Salario en criptomonedas. Deloitte España. Recuperado el 11 de abril de $2021 \mathrm{de}$ https://www2.deloitte.com/es/es/pages/legal/articles/salario-encriptomonedas.html

El BCU estudiará costos del sistema y regulará criptomonedas. (22 de octubre de 2020). Búsqueda. Recuperado el 23 de abril de 2021 de https://www.busqueda.com.uy/Secciones/El-BCU-estudiara-costos-del-sistema-yregulara-criptomonedas-uc2031

Garrido, F. (29 de marzo de 2021). Argentina y España venden sus primeras propiedades en criptomonedas. Ámbito. Recuperado el 23 de abril de 2021 de https://www.ambito.com/finanzas/criptomonedas/argentina-y-espana-venden-susprimeras-propiedades-n5180262

Goldman Sachs planea incursionar en la custodia de criptomonedas. (18 de enero de 2021). Criptonoticias. Recuperado el 23 de abril de 2021 de https://www.criptonoticias.com/negocios/goldman-sachs-planea-incursionar-custodiacriptomonedas/

Grupo de Acción Financiera Internacional. (s. f.). Recomendación 15. Nuevas tecnologías. 40 recomendaciones del GAFI. Recuperado el 23 de abril de 2021 de https://www.cfatfgafic.org/index.php/es/documentos/gafi40-recomendaciones/421-fatf-recomendacion15-nuevas-tecnologias

Hayek, F. (1996). La desnacionalización del dinero. Buenos Aires, Argentina: Unión. 
Huillet, M. (11 de febrero de 2021). El banco más antiguo de Estados Unidos, BNY Mellon, custodiará Bitcoin. Cointelegraph. Recuperado el 23 de abril de 2021 de https://es.cointelegraph.com/news/america-s-oldest-bank-bny-mellon-will-custodybitcoin

James, R. (21 de febrero de 2021). Oro vs Bitcoin como inversión a largo plazo ¿Qué opinan los expertos? BeInCrypto. Recuperado el 23 de abril de 2021 de https://es.beincrypto.com/oro-vs-bitcoin-btc-como-inversion-largo-plazo-que-opinanexpertos/

López, M. (8 de abril de 2021). Starbucks comenzará a aceptar criptomonedas como método de pago. Bitfinanzas. Recuperado el 23 de abril de 2021 de https://bitfinanzas.com/starbucks-comenzara-a-aceptar-criptomonedas-como-metodode-pago/

Mastercard se suma a la 'fiebre' de las criptomonedas y comenzará a permitir pagos con ellas a lo largo de 2021. (11 de febrero de 2021). El Economista. Recuperado el 23 de abril de $2021 \mathrm{de} \mathrm{https://www.eleconomista.es/empresas-}$ finanzas/noticias/11044365/02/21/Mastercard-se-suma-a-la-fiebre-de-lascriptomonedas-y-comenzara-a-permitir-pagos-con-ellas-a-lo-largo-de-2021.html

Méndez, B. (3 de febrero de 2021). Primera tarjeta de débito de criptomonedas en Argentina con pesos y reintegros Bitcoin. BeInCrypto. Recuperado el 23 de abril de 2021 de https://es.beincrypto.com/primera-tarjeta-debito-criptomonedas-argentina-pesosreintegros-bitcoin-btc/

Menger, C. (1892). El origen del dinero. Recuperado de https://www.eumed.net/cursecon/textos/Menger-origen-dinero.pdf

Pérez, H. (27 de marzo de 2021). ¿Cómo se establece el precio de Bitcoin y por qué puede variar entre exchanges? DiarioBitcoin. Recuperado el 23 de abril de 2021 de https://www.diariobitcoin.com/mercados/bitcoin-mercados/como-se-establece-elprecio-de-bitcoin-y-por-que-puede-variar-entre-exchanges/

Plá Rodríguez, A. (1956). El Salario en el Uruguay, Tomo II. Montevideo, Uruguay: Martín Bianchi Altuna.

Plá Rodríguez, A. (1994). Curso Derecho Laboral, Tomo III, vol. II. Montevideo, Uruguay: Idea.

Presentamos Binance Card: compre y pague con criptomonedas en cualquier parte del mundo. (25 de marzo de 2020). Binance. Recuperado el 23 de abril de 2021 de https://www.binance.com/es/blog/421499824684900479/Presentamos-Binance-Cardcompre-y-pague-con-criptomonedas-en-cualquier-parte-del-mundo

Ramírez, P. (30 de marzo de 2021). ¿Puedo cobrar mi sueldo en bitcoins? El curioso caso que estudian las empresas. La Información. Recuperado de https://www.lainformacion.com/management/cobrar-sueldo-bitcoins-retribucionespecie-criptomonedas/2833749/

Sánchez, Á. (8 de febrero de 2021). Tesla invierte 1.250 millones en bitcoins y aceptará pagos en la criptodivisa. El País. Recuperado el 23 de abril de 2021 de https://elpais.com/economia/2021-02-08/tesla-invierte-1250-millones-de-euros-enbitcoins-y-aceptara-pagos-en-la-criptodivisa.html 
Securities and Exchange Commission v. Shavers et al, No. 4:2013cv00416 - Document 88 (E.D. Tex. 2014). (2021). Recuperado el 23 de abril de 2021 de https://law.justia.com/cases/federal/districtcourts/texas/txedce/4:2013cv00416/146063/88/

Suberg, W. (11 de agosto de 2020). La mayor empresa de inteligencia de negocios del mundo compra 21,000 Bitcoin por USD 250 millones. (2021). Cointelegraph. Recuperado el 23 de abril de 2021 de https://es.cointelegraph.com/news/worlds-biggest-businessintelligence-firm-buys-21k-btc-for- $250 \mathrm{~m}$

Villullas, C. (15 de febrero de 2021). Miami y Nueva York piensan en Bitcoin para el pago de salarios y cobro de impuestos. Bit2me. Recuperado el 23 de abril de 2021 de https://news.bit2me.com/miami-nueva-york-bitcoin-inversion-salarios-impuestos

Von Mises, L. (1997). La teoría del dinero y del crédito. Buenos Aires, Argentina: Unión.

Weatherford, J. (1998). La historia del dinero. De la piedra arenisca al ciberespacio. Santiago de Chile, Chile: Andrés Bello.

Wright, T. (10 de febrero de 2021). Twitter considera pagos con Bitcoin para los empleados, dice el director financiero. Cointelegraph. Recuperado el 23 de abril de 2021 de https://es.cointelegraph.com/news/twitter-looking-into-bitcoin-payments-foremployees-says-cfo

Yelpo, A. (2018a). Monedas digitales. Régimen aplicable [Powerpoint]. Presentado en Jornadas Anuales de Derecho Bancocentralista. Recuperado el 23 de abril de 2021de https://www.bcu.gub.uy/Comunicaciones/Jornadas_de_Derecho_BCU/Presentaciones_ 2018/Dra\%20Andrea\%20Yelpo.ppt

Yelpo, A. (2018b). Dinero electrónico, criptomonedas y sistema de pagos. Montevideo, Uruguay: La Ley Uruguay.

\section{Contribución autoral}

a) Concepción y diseño del trabajo; b) Adquisición de datos; c) Análisis e interpretación de datos; d) Redacción del manuscrito; e) revisión crítica del manuscrito.

J. D. ha contribuido en a, b, c, d, e; G. G. ha contribuido en a, b, c, d, e.

Editor científico responsable: Dra. María Paula Garat. 